\title{
Gypenosides protect against cardiac ischemia-reperfusion injury by inhibiting mitochondria-dependent apoptosis
}

\author{
Song Qiao ${ }^{1}$, Xinwen $\mathrm{Liu}^{2 \star}$, Longsheng Chen ${ }^{3}$ \\ ${ }^{1}$ Department of Neurology, ${ }^{2}$ Department of Cardiology, Zhejiang Hospital, Hangzhou 310013, ${ }^{3}$ Department of Gastroenterology, \\ The 3rd People's Hospital of Deqing County, Huzhou, 313201, China
}

*For correspondence: Email: Liuxinwrose@126.com

Sent for review: 4 May 2018

Revised accepted: 28 July 2018

\begin{abstract}
Purpose: To investigate the effect of gypenoside (Gyp) on myocardial ischemia-reperfusion (I/R), focusing on mitochondrial function and oxidative stress.

Methods: A 3-(4,5-Dimethyl-2-thiazolyl)-2,5-diphenyl-2H-tetrazolium bromide methylthiazolyldiphenyltetrazolium bromide (MTT) assay was employed to measure the protective effect of Gyp pre-treatment against I/R injury. Flow cytometry was used to detect cellular reactive oxygen species (ROS) content and mitochondrial membrane potential (MMP) levels. Additionally, cytochrome $C$ release was observed by laser scanning confocal microscopy. Finally, Annexin V staining and western blot were applied to analyse cell apoptosis.

Results: MTT assay results showed that Gyp pre-treatment protected H9C2 cells against I/R injury in a Gyp concentration-dependent manner. Moreover, Gyp treatment inhibited intracellular ROS production, repressed cytochrome $C$ transposition induced by $I / R$ treatment, and recovered MMP to almost normal levels. Furthermore, the expression of apoptosis-related proteins included cleaved caspase-3, -9 and Bax which were decreased by Gyp treatment after I/R injury.

Conclusion: These results suggest that Gyp treatment prior to injury can help maintain normal mitochondrial function and inhibit ROS production during I/R injury, ultimately leading to the suppression of I/R-induced cell apoptosis. Thus, Gyp may be a promising drug for the treatment of myocardial I/R.
\end{abstract}

Keywords: Gynostemma pentaphyllum, Ischemia-reperfusion, Mitochondria damage, Oxidative stress, Apoptosis

This is an Open Access article that uses a funding model which does not charge readers or their institutions for access and distributed under the terms of the Creative Commons Attribution License (http://creativecommons.org/licenses/by/4.0) and the Budapest Open Access Initiative (http://www.budapestopenaccessinitiative.org/read), which permit unrestricted use, distribution, and reproduction in any medium, provided the original work is properly credited.

Tropical Journal of Pharmaceutical Research is indexed by Science Citation Index (SciSearch), Scopus, International Pharmaceutical Abstract, Chemical Abstracts, Embase, Index Copernicus, EBSCO, African Index Medicus, JournalSeek, Journal Citation Reports/Science Edition, Directory of Open Access Journals (DOAJ), African Journal Online, Bioline International, Open-J-Gate and Pharmacy Abstracts

\section{INTRODUCTION}

Cardiovascular dysfunction, including acute myocardial infarction and cardiac failure, is a leading cause of morbidity and mortality worldwide. Common treatment strategies for cardiovascular disease include pharmacological intervention, mechanical coronary reperfusion, and surgery [1]. Transient occlusion of a coronary artery damages myocardial cells because of ischemic insult and energy exhaustion; however, the reperfusion of blood to myocardium also causes severe tissue injury, called ischemia-reperfusion (I/R) injury [1-3]. And $\mathrm{I} / \mathrm{R}$ injury is a complex pathological event, which is still not well-characterized. Research indicates that several external stimuli, such as 
mitochondrial dysfunction, reactive oxygen species (ROS) release, loss of energy supply, inflammation, microcirculatory disorder, oedema, and cell apoptosis, contribute to I/R injury [4-6]. Because of the complexity of this phenomenon, any treatment that targets a single contributing factor will be insufficient to provide comprehensive therapy.

Recent research suggested that components used in traditional Chinese medicine are protective in $\mathrm{I} / \mathrm{R}$ injury $[7,8]$. One such medicinal herb, Gynostemma pentaphyllum, is popularly used to treat chronic inflammation, cancer, cardiovascular disease, and hepatitis. In $\mathrm{I} / \mathrm{R}$ injured rats, $G$. pentaphyllum was found to reduce impairment of cardiac function. Yu et al reported that $G$. pentaphyllum treatment prior to cardiac insult inhibits IKB- $\alpha$ phosphorylation, translocation of the nuclear factor kappa $B$ (NFKB) subunit into nuclei, and MAPK pathway activity [9]. Ye et al showed that gypenoside (Gyp), an important component of $G$. pentaphyllum, protects the kidneys from $\mathrm{l} / \mathrm{R}$ injury by inhibiting inflammation, apoptosis, and ERK signalling [10].

Gyp has various biological activities, including roles in anti-inflammatory reactions, insulin resistance, reducing memory deficits, and decreasing liver fibrosis [11,12]. Moreover, Gyp IX inhibits NFKB transcriptional activity and reduced the expression of several inflammatory factors, including nitric oxide synthase (iNOS), tumour necrosis factor- $\alpha$ (TNF- $\alpha$ ), and interleukin-1 $\beta$ (IL-1 $\beta$ ) [11]. Qin and colleagues showed that Gyp influences lipid metabolism, reduces oxidative stress, inhibits mitochondrial damage, and prevents degeneration in fatty liver disease [13]. Also, Gyp is reported to protect the brain against I/R damage.

Preliminary evidence suggests that Gyp is a promising drug candidate for $\mathrm{I} / \mathrm{R}$ therapy, but the role of Gyp in cardiac I/R injury has not been rigorously explored. In this paper, the effects of Gyp were investigated in cardiac I/R, focusing on mitochondrial function and oxidative stress.

\section{EXPERIMENTAL}

\section{Cell culture}

H9C2 cells (CRL-1446) were purchased from ATCC. Dulbecco's modified Eagle medium (HyClone, USA) with $10 \%$ foetal bovine serum (HyClone, USA) and $1 \%$ penicillin and streptomycin (HyClone, USA)was used to culture H9C2 cells.

\section{Chemicals}

Gyp was purchased from Jiatian Biotechnology Co. Ltd (Xi'an, Shaanxi Province, China). Dimethyl sulfoxide (DMSO), 3-(4,5-dimethylthiazol-2-yl)-2,5-diphenyltertrazolium bromide tetrazolium (MTT), and rhodamine-123 (Rh123) were obtained from Sigma-Aldrich. The 2',7'dichlorodihydrofluorescein-diacetate (DCFH-DA) probe was purchased from Invitrogen (USA), and the Annexin V-FITC Apoptosis Detection kit was purchased from KeyGEN BioTECH Corp, Ltd.

\section{Cell preparation and Gyp pre-treatment}

To imitate $\mathrm{I} / \mathrm{R}$ injury, cells were cultured in glycoprival medium without serum and exposed to $0.5 \% \mathrm{O}_{2}$ (oxygen deprivation), followed by reoxygenation under normal oxygen conditions in complete culture medium for $24 \mathrm{~h}$ to mimic myocardial I/R. For Gyp treatment groups, Gyp $(5,10,20$, and $40 \mu \mathrm{g} / \mathrm{mL})$ was added to the medium $12 \mathrm{~h}$ before the $\mathrm{l} / \mathrm{R}$ treatment, and untreated cells were used as the control group.

\section{Cell viability assessment}

After 24 and $48 \mathrm{~h}$ of reperfusion treatment, cell viability was detected by MTT assay. H9C2 cells were seeded in 96-well plates overnight, and then the old culture medium was replaced by the new culture medium containing the indicated Gyp concentration. After another 12-h incubation, the medium was replaced with glycoprival DMEM with Gyp. After a 4-h incubation at $0.5 \% \mathrm{O}_{2}$, the glycoprival DMEM was removed, and complete culture medium that also contained Gyp was added. Cells were then subjected to $\mathrm{I} / \mathrm{R}$ stimulus. Then, 24 and $48 \mathrm{~h}$ after $\mathrm{l} / \mathrm{R}, 50 \mu \mathrm{g}$ MTT was added to each well. After $4 \mathrm{~h}$, the mixed cell culture medium was replaced with DMSO to dissolve formazan crystals, and was used to calculate the cell survival rate (C) spectrophotometrically as in Eq 1.

$C(\%)=(\mathrm{At} / \mathrm{Ac}) 100$

where At and Ac are the absorbance of treatment and control groups, respectively.

\section{Intracellular ROS determination}

DCFH-DA was used to measure ROS levels in the different cell groups, as previously described [14]. Two hours after I/R treatment, cells in each group were cleaned with phosphate buffered saline (PBS) three times, then stained with $4 \mu \mathrm{M}$ DCHF-DA diluted in DMEM at $37^{\circ} \mathrm{C}$ for $20 \mathrm{~min}$. Then, the cells were harvested and cleaned with 
PBS. Cell samples were analysed by flow cytometry.

\section{Mitochondrial membrane potential (MMP) determination}

Rhodamine 123 (Rho 123) staining was used to measure cell MMP, as previously described [15]. Two hours after treatment, cells were harvested and stained with $1 \mu \mathrm{g} / \mathrm{mL}$ Rho 123 at $37^{\circ} \mathrm{C}$ for $20 \mathrm{~min}$. After staining, all samples were analysed by using flow cytometry.

\section{Cytochrome c release analysis}

Cells were seeded in 6-well plates, grown overnight, pre-incubated with Gyp at the indicated concentration, and then subjected to treatment to mimic I/R injury. After $2 \mathrm{~h}$, the cells were cleaned with PBS and stained with $0.5 \mathrm{mM}$ Mito-Tracker Red (MTR, Molecular Probes). After $20 \mathrm{~min}$, the cells were fixed with $4 \%$ paraformaldehyde, followed by the addition of 0.1 $\%$ Triton X-100 at $4{ }^{\circ} \mathrm{C}$. After being permeabilized, samples were blocked with goat serum for $1 \mathrm{~h}$ at $37^{\circ} \mathrm{C}$, then incubated with anticytochrome $\mathrm{C}$ antibody at $4{ }^{\circ} \mathrm{C}$ overnight. Cytochrome c antibody was labelled by fluorescein isothiocyanate (FITC) conjugated secondary antibody. Cell nucleus were stained with Hoechst 33258 and imaged with a confocal laser scanning microscope.

\section{Western blot analysis}

After I/R treatment, cells were lysed with radioimmunoprecipitation assay (RIPA) buffer, and then total protein content in the lysate was measured using a Bradford assay. Proteins levels for each treatment group were determined according to western blot standard procedures. Quantification of protein expression was normalized to a $\beta$-actin loading control.

\section{Apoptosis assay}

Cell apoptosis was investigated using an Annexin V/FITC-propidium iodide (PI) kit. Briefly, cells for all treatment groups were harvested and then washed twice with PBS. Then, cells were stained with Annexin V-FITC and PI at $37^{\circ} \mathrm{C}$ for $20 \mathrm{~min}$. After staining, all samples were detected by flow cytometry.

\section{Statistical analysis}

All data are expressed as mean \pm standard deviation ( $S D, n=3)$ ). Statistical significance was calculated using one-way analysis of variance. A value of $p<0.05$ was used to determine a significant difference between groups. SPSS 19.0 software was used for statistical analysis.

\section{RESULTS}

\section{Cell viability}

The MTT assay was applied to evaluate the cytotoxicity of the different treatments. As shown in Figure 1, $24 \mathrm{~h}$ after I/R injury, cell viability was $35.00 \%$. Pre-treatment with Gyp rescued the cytotoxicity induced by I/R-mimic treatment. In cells pre-treated with Gyp at 5, 10, 20, and 40 $\mu \mathrm{g} / \mathrm{mL}$, cell viability $24 \mathrm{~h}$ after I/R-mimic treatment was 38.67, 49.00, 71.67, and $81.06 \%$, respectively. When the incubation time was increased to $48 \mathrm{~h}$, the cell survival was slightly higher than that $24 \mathrm{~h}$ after treatment. After $48 \mathrm{~h}$, cell viability increased to $57.67,67.00,79.28$, and $91.63 \%$ for Gyp concentrations of 5, 10, 20, and $40 \mu \mathrm{g} / \mathrm{mL}$, respectively. These results suggest that pre-treatment with Gyp protects H9C2 cells from $I / R$ injury in a time- and concentration-dependent manner.

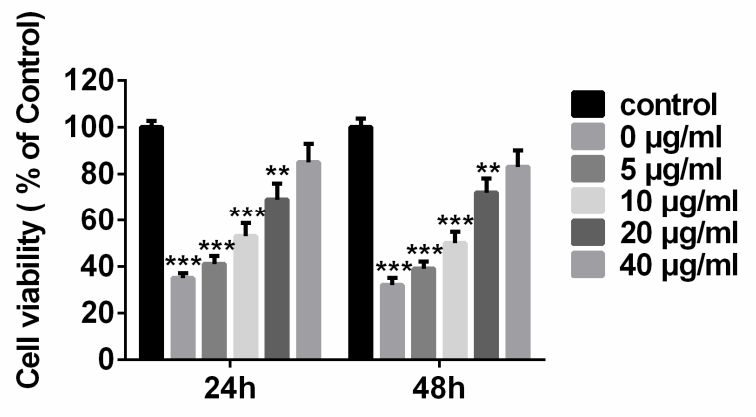

Figure 1: $\mathrm{H} 9 \mathrm{C} 2$ cell viability after I/R-mimic treatment. Cell viability was measured by MTT assay 24 and $48 \mathrm{~h}$ after Gyp treatment at the indicated concentrations. Results are expressed as mean $\pm \operatorname{SD}(n=3)$

\section{ROS}

Intracellular ROS in $\mathrm{H} 9 \mathrm{C} 2$ cells was measured 2 $\mathrm{h}$ after the different treatments. As shown in Figure 2, I/R-mimic treatment increased the intracellular ROS production to $54.5 \%$ from 19.7 $\%$ that was observed in the control group. Gyp treatment decreased the ROS production that resulted from I/R-mimic treatment: treatment with $10 \mu \mathrm{g} / \mathrm{mL}$ Gyp reduced the subset of cells with high ROS production to $48.7 \%$. When Gyp concentration was increased to 20 and 40 $\mu \mathrm{g} / \mathrm{mL}$, the percentage of cells with high ROS production further decreased to $36.7 \%$ and 21.8 $\%$, respectively. 


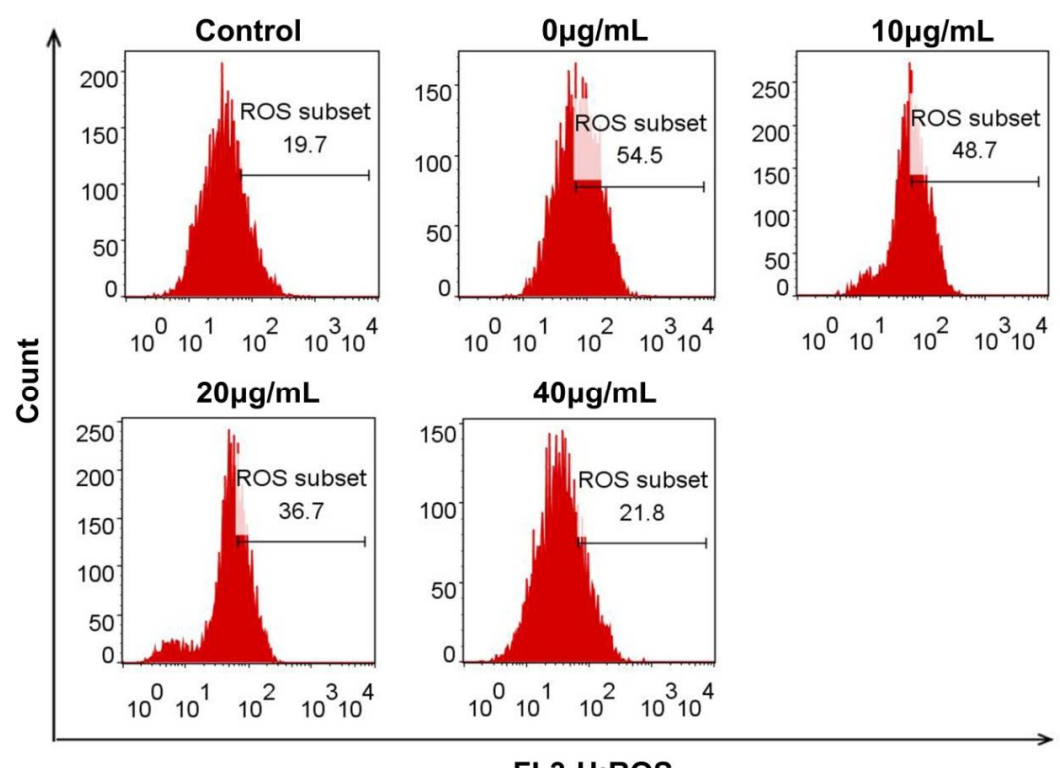

\section{FL3-H:ROS}

Figure 2: Intracellular ROS production after I/R injury at different concentrations of Gyp treatment
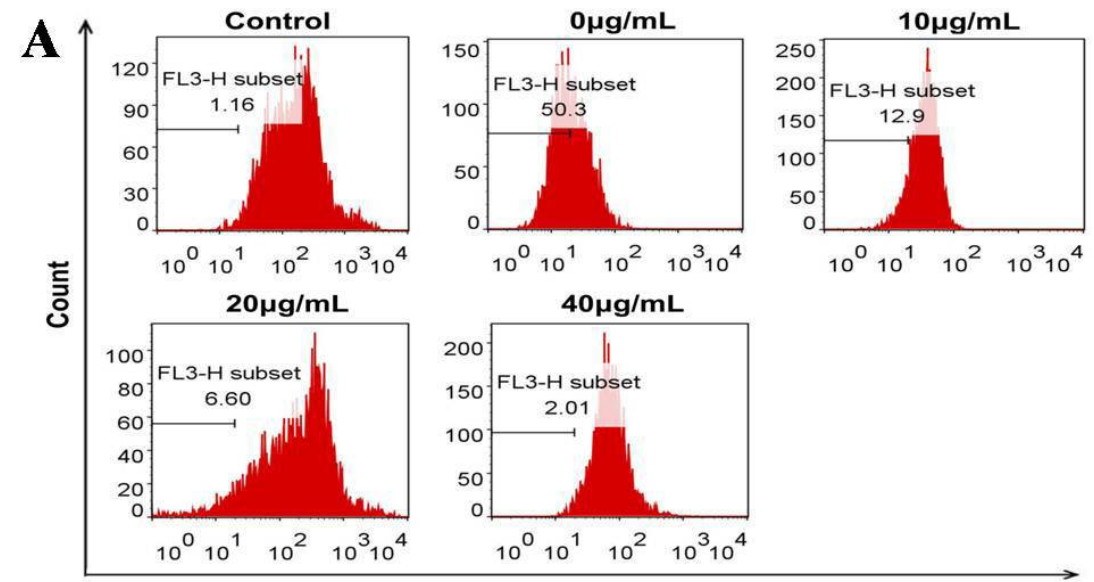

FL3-H

B

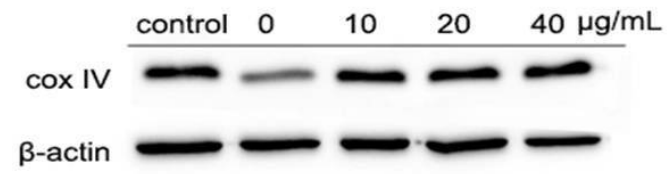

Figure 3: The effect of Gyp treatment on mitochondrial damage in $\mathrm{l} / \mathrm{R}$ mimic-treated myocardial cells. (A) Measurement of mitochondrial membrane potential by Rho 123 staining. (B) COX IV protein expression detected by western blot

\section{Gyp treatment protects cell mitochondria}

$\mathrm{I} / \mathrm{R}$ injury damages cell mitochondria and disturbs the process of ATP generation, resulting in cell death. In this study, cell MMP was measured $2 \mathrm{~h}$ after I/R-mimic treatment. As shown in Figure 3A, MMP decreased in the $\mathrm{I} / \mathrm{R}$ mimic-treated group; $50.3 \%$ cells showed lower MMP following I/R injury. Treatment with $10 \mu \mathrm{g} / \mathrm{ml}$ Gyp rescued the loss of MMP, as only $12.9 \%$ of cells showed lower MMP. Furthermore, higher Gyp concentrations further inhibited the MMP decrease that resulted from I/R-mimic treatment. Specifically, $40 \mu \mathrm{g} / \mathrm{ml}$ Gyp treatment nearly recovered MMP to a normal level. In order to further assess mitochondrial function, we measured expression of the cytochrome oxidase complex IV (COX IV), which is an important component of the respiratory chain. I/R-mimic treatment decreased COX IV expression (Figure $3 \mathrm{~B})$, indicating serious mitochondrial damage. COX IV expression levels increased with increasing concentrations of Gyp treatment (Figure 3B).

\section{Cytochrome $\mathrm{C}$ release}

Cytochrome $\mathrm{C}$ release was also observed in 
each group after treatment (Figure 4). In control cells, MTR labelling with red fluorescence and cytochrome $c$ labelling with green fluorescence showed considerable overlap. Although cells in the I/R-mimic treatment group showed partial release of cytochrome $\mathrm{C}$ green fluorescence from the mitochondria to the cytoplasm, cells treated with $40 \mu \mathrm{g} / \mathrm{mL}$ Gyp exhibited decreased cytochrome c green fluorescence in the cytoplasm after I/R-mimic treatment.

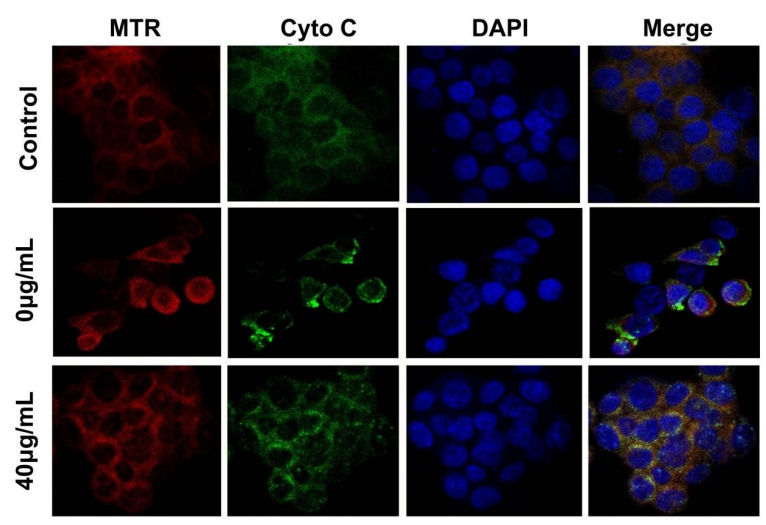

Figure 4: The effect of Gyp on cytochrome c transposition in myocardial cells after I/R-mimic treatment. After Gyp treatment, I/R mimic-treated myocardial cells were stained with Mito-Tracker Red (MTR; mitochondrial probe, red channel), cytochrome c antibody (green channel), and DAPI (blue channel). After staining, cells were observed by confocal microscopy.

\section{Gyp treatment on cell apoptosis}

Mitochondrial damage, evidenced by cytochrome c release, can initiate mitochondria-dependent apoptosis [16]. Annexin V staining indicates both early and late apoptosis, in contrast to $\mathrm{PI}$ staining, which only labels necrotic cells. We found that the control group exhibited $93.2 \%$ viable cells and $6.34 \%$ apoptotic cells (Figure $5 A)$. In the $\mathrm{l} / \mathrm{R}$ mimic-treated group, the cell viability decreased to $37.3 \%$, with an increased apoptosis rate of $53.84 \%$ and debris rate of 8.9 $\%$. In cells treated with $10 \mu \mathrm{g} / \mathrm{ml}$ Gyp, cell viability increased to $63.1 \%$, and apoptosis decreased to $35.0 \%$. In the cells treated with 20 and $40 \mu \mathrm{g} / \mathrm{mL}$ Gyp, we observed that cell viability further increased to 71.1 and $78.5 \%$, respectively, and the apoptosis frequency decreased to 25.59 and $20.76 \%$, respectively. In addition, the apoptosis-related proteins cleaved caspase-3, -9 , and Bax, which were significantly upregulated in the I/R mimic-treated group. We found that Gyp treatment decreased expression of these proteins in a concentration-dependent manner. In contrast, Gyp treatment resulted in an increase in expression of the anti-apoptosis protein Bcl-2. These data indicate that an I/R stimulus can cause cell apoptosis and that Gyp treatment can rescue these apoptosis effects.
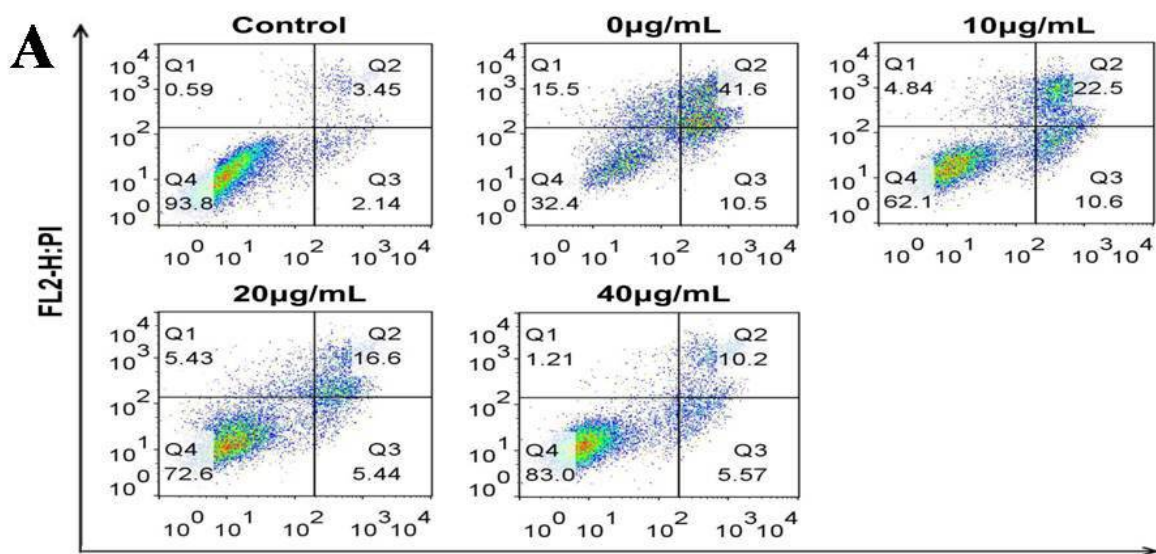

FLI-H:Annexin V-FITC

B

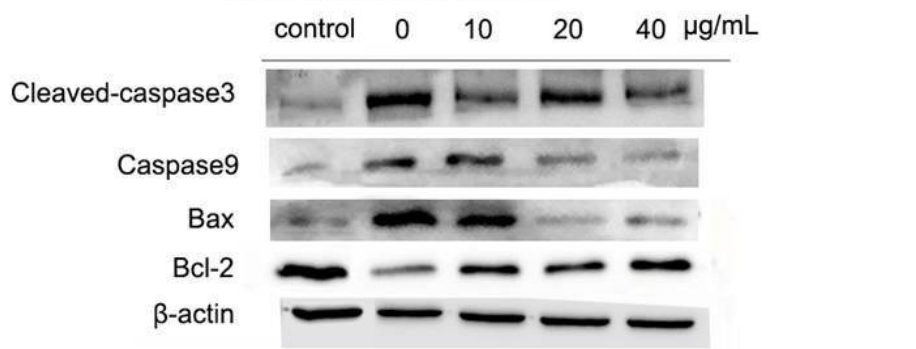

Figure 5: The effect of Gyp treatment on apoptosis in I/R mimic-treated myocardial cells. (A) Frequency of cell apoptosis in I/R mimic-treated myocardial cells by Annexin V-FITC/PI staining. (B) Cleaved caspase-3, -9, Bax, and Bcl-2 in I/R mimic-treated myocardial cells after Gyp pre-treatment. Representative images of western blots are shown 


\section{DISCUSSION}

The I/R-mimic treatment used in this study caused cellular injury, including increased ROS production, mitochondrial damage, and energy depletion. Mitochondrial dysfunction is one of the most important causes of tissue damage, especially in myocardial cells [17]. Gyp treatment is known to relieve oxidative stress and protect mitochondria [18]. This study focused on the effect of Gyp pre-treatment on protecting heart tissue against an I/R-mimic treatment. Results showed that Gyp inhibited cell damage associated with I/R-mimic treatment in a manner dependent on Gyp concentration, indicating that Gyp has potential to protect myocardial cells against I/R injury.

$\mathrm{I} / \mathrm{R}$ injury induces severe oxidative stress [19], which can cause abnormal platelet function and dysfunctional endothelium-dependent vasodilatation [20]. Abundant ROS also cause oxidative damage of cell lipids, proteins, and DNA as well as mitochondrial dysfunction and loss of membrane integrity. Much research has been conducted on the effect of reducing ROS production during $\mathrm{I} / \mathrm{R}$ injury [21]. Wicha et al reported that treatment with hexahydrocurcumin protected cerebral against $\mathrm{I} / \mathrm{R}$ injury by attenuating oxidative stress, increasing nuclear factor (erythroid-derived 2)-like 2 (Nrf2) and heme oxygenase-1 (HO-1) expression levels, and improving the activity of antioxidant enzymes [22]. Zhen et al found that exendin-4 activated the Nrf2 anti-oxidative signalling pathway and alleviated kidney $\mathrm{l} / \mathrm{R}$ injury by suppressing oxidative stress [23]. In the present study, abundant ROS was found in H9C2 cells after l/Rmimic treatment. Gyp pre-treatment decreased cellular ROS levels in a concentration-dependent manner, consistent with our cell viability data. This result highlights the important role of ROS in myocardial cell death caused by I/R injury.

Mitochondria contribute to energy production and are involved in cell stress pathways. In myocardial I/R injury, mitochondria are key targets of damage and important regulators of the response to damage. During ischemia, the electron transport chain is firstly severely damaged, then the mitochondrial respiration chain complexes are compromised, and finally oxidative phosphorylation is decreased [22]. During the ischemic stage, both excessive ROS and calcium dysregulation cause mitochondria permeation changes, concomitant with swelling and disruption of the mitochondrial permeability transition pore. After an extended period of ischemia, $\quad l / R$ injury can also cause morphological changes and loss of mitochondria
[22]. In cells receiving the $\mathrm{I} / \mathrm{R}$-mimic treatment, MMP and expression of COX IV decreased, indicating serious mitochondrial injury. With Gyp pre-treatment at increasing concentrations, decreased MMP and expression of COX IV were gradually rescued.

Several reports have indicated that the damaged mitochondria may subsequently drive cells to initiate the apoptotic process [24]. We found that the mitochondrial marker MTR co-localized with cytochrome $\mathrm{c}$ in the control cells, and after I/Rmimic treatment, cytochrome $\mathrm{c}$ was released from the mitochondria to the cytoplasm. The Annexin V-FITC/PI assay revealed that $53.84 \%$ of the cells were apoptotic after l/R-mimic treatment, in accord with caspase-3 and -9 activation. Gyp treatment decreased apoptosis frequency and expression of apoptosis-related proteins in the $1 / R$ mimic-treated group. As mentioned above, I/R-mimic treatment induced mitochondria-dependent apoptosis in $\mathrm{H} 9 \mathrm{C} 2$ cells, and Gyp pre-treatment decreased this I/Rassociated apoptosis.

\section{CONCLUSION}

The findings of this study demonstrate that Gyp pre-treatment protects myocardial cells against I/R-mimic treatment. Gyp pre-treatment helps maintain mitochondrial function and inhibits ROS production during $\mathrm{I} / \mathrm{R}$-mimic stimulus, resulting in suppression of cell apoptosis caused by $\mathrm{I} / \mathrm{R}$. Thus, Gyp treatment provides a promising strategy for the management of cardiac $\mathrm{I} / \mathrm{R}$ injury.

\section{DECLARATIONS}

\section{Conflict of Interest}

No conflict of interest associated with this work.

\section{Contribution of Authors}

We declare that this work was done by the authors named in this article and all liabilities pertaining to claims relating to the content of this article will be borne by the authors. Xinwen Liu designed all the experiments and revised the paper. Song Qiao and Longsheng Chen performed the experiments, and Song Qiao wrote the paper.

\section{REFERENCES}

1. Zou R, Shi W, Tao J, Li H, Lin X, Yang S, Hua P. SIRT5 and post-translational protein modifications: $A$ potential therapeutic target for myocardial ischemia-reperfusion 
injury with regard to mitochondrial dynamics and oxidative metabolism. Eur J Pharmacol 2017; 818: 410418.

2. Choi EK, Baek J, Park S, Baek SH, Choi JH, Lee CH, Sung $E G$, Jee $D$. Preischemic transfusion of old packed $R B C s$ exacerbates early-phase warm hepatic ischemia reperfusion injury in rats. J Surg Res 2018; 222: 26-33.

3. Hu YQ, Chen W, Yan MH, Lai JJ, Tang N, Wu L. Ischemic preconditioning protects brain from ischemia/reperfusion injury by attenuating endoplasmic reticulum stress-induced apoptosis through PERK pathway. Eur Rev Med Pharmacol Sci 2017; 21(24): 5736-5744.

4. Chen $H$, Song Z, Ying S, Yang X, Wu W, Tan Q, Ju X, Wu W, Zhang $X, Q u$ J. Myeloid differentiation protein 2 induced retinal ischemia reperfusion injury via upregulation of ROS through a TLR4-NOX4 pathway. Toxicol Lett 2017; 282

5. Li S, Wang T, Zhai L, Ge K, Zhao J, Cong W, Guo Y. Picroside II Exerts a Neuroprotective Effect by Inhibiting mPTP Permeability and EndoG Release after Cerebral Ischemia/Reperfusion Injury in Rats. J Mol Neurosci 2018; 64(1): 144-155.

6. Pisarenko O, Timotin A, Sidorova M, Studneva I, Shulzhenko $V$, Palkeeva $M$, Serebryakova $L$, Molokoedov A, Veselova O, Cinato M. Cardioprotective properties of $\mathrm{N}$-terminal galanin fragment (2-15) in experimental ischemia/reperfusion injury. Oncotarget 2017; 8(60): 101659-101671.

7. Deng $X$, Xing $X$, Sun $G, X u X, W u H$, Li G, Sun $X$. Guanxin Danshen Formulation Protects against Myocardial Ischemia Reperfusion Injury-Induced Left Ventricular Remodeling by Upregulating Estrogen Receptor $\beta$. Front Pharmacol 2017; 8: 777-784.

8. Li L, Wang N, Jin Q, Wu Q, Liu Y, Wang Y. Protection of Tong-Qiao-Huo-Xue Decoction against Cerebral Ischemic Injury through Reduction Blood-Brain Barrier Permeability. Chem Pharm Bull 2017; 65(11): 10041010.

9. Yu H, Shi L, Qi G, Zhao S, Gao Y, Li Y. Gypenoside Protects Cardiomyocytes against Ischemia-Reperfusion Injury via the Inhibition of Mitogen-Activated Protein Kinase Mediated Nuclear Factor Kappa B Pathway In Vitro and In Vivo. Front Pharmacol 2016; 7(e21891): 148-158.

10. Ye $Q$, Zhu $Y$, Ye S, Liu $H$, She $X$, Niu $Y$, Ming $Y$. Gypenoside attenuates renal ischemia/reperfusion injury in mice by inhibition of ERK signaling. Exp Ther Medic 2016; 11(4): 1499-1505.

11. Wang $X$, Yang L, Yang L, Xing $F$, Yang $H$, Qin L, Lan $Y$, Wu H, Zhang B, Shi H. Gypenoside IX Suppresses p38 MAPK/Akt/NFKB Signaling Pathway Activation and Inflammatory Responses in Astrocytes Stimulated by Proinflammatory Mediators. Inflammation 20172): 1-14.

12. Chen J, Li X, Hu Y, Liu W, Zhou Q, Zhang H, Mu Y, Liu $P$. Gypenosides Ameliorate Carbon TetrachlorideInduced Liver Fibrosis by Inhibiting the Differentiation of
Hepatic Progenitor Cells Into Myofibroblasts. Am J Chin Medic 2017; 45(5): 1061-1074.

13. Qin R, Zhang J, Li C, Zhang X, Xiong A, Huang F, Yin Z, Li K, Qin W, Chen M. Protective effects of gypenosides against fatty liver disease induced by high fat and cholesterol diet and alcohol in rats. Arc Pharm Res 2012; 35(7): 1241-1250.

14. Zhang $P$, Zhao SR, Liu F, Sun XJ, Liu H. Oridonin Induces Apoptosis in Human Nasopharyngeal Carcinoma Cells Involving ROS Generation. Folia Biol 2017; 63(4): 155-163.

15. Zhang WG, Liu XF, Meng KW, Hu SY. Puerarin inhibits growth and induces apoptosis in SMMC-7721 hepatocellular carcinoma cells. Mol Med Rep 2014; 10(5): 2752-2758.

16. Ma ZJ, Lu L, Yang JJ, Wang XX, Su G, Wang ZL, Chen $G H$, Sun HM, Wang MY, Yang $Y$. Lariciresinol induces apoptosis in HepG2 cells via mitochondrial-mediated apoptosis pathway. Eur J Pharmacol 2018; 821: 1-10.

17. Lesnefsky EJ, Chen Q, Tandler B, Hoppel CL. Mitochondrial Dysfunction and Myocardial IschemiaReperfusion: Implications for Novel Therapies. Annu Rev Pharmacol Toxicol 2017; 57(1): 535-565.

18. $Y u H$, Guan $Q$, Guo L, Zhang $H$, Pang $X$, Cheng $Y$, Zhang $X$, Sun $Y$. Gypenosides alleviate myocardial ischemia-reperfusion injury via attenuation of oxidative stress and preservation of mitochondrial function in rat heart. Cell Stress Chaperone 2016; 21(3): 1-9.

19. Neto SF, Ikejiri AT, Bertoletto PR, Chaves JC, Teruya R, Fagundes DJ. Hyperbaric oxygenation and the genic expression related to oxidative stress in the heart of mice during intestinal ischemia and reperfusion. Acta Cir Bras 2017; 32(11): 913-923.

20. Zuluaga M, Gueguen V, Letourneur D, Pavondjavid G. Astaxanthin-antioxidant impact on excessive Reactive Oxygen Species generation induced by ischemia and reperfusion injury. Chem Biol Interact 2017; 279: 145158.

21. $Q u Y$, Zhang $H L$, Zhang $X P$, Jiang HL. Arachidonic acid attenuates brain damage in a rat model of ischemia/reperfusion by inhibiting inflammatory response and oxidative stress. Hum Exp Toxicol 2018; 37(2): 135-141.

22. Wicha $P$, Tocharus J, Janyou A, Jittiwat J, Changtam $C$, Suksamrarn A, Tocharus C. Hexahydrocurcumin protects against cerebral ischemia/reperfusion injury, attenuates inflammation, and improves antioxidant defenses in a rat stroke model. Plos One 2017; 12(12): e0189211.

23. Zhen $Y Y$, Yang $C C$, Hung $C C$, Lee $C C$, Lee $C C, W u C H$, Chen YT, Chen WY, Chen KH, Yip HK. Extendin-4 protects kidney from acute ischemia-reperfusion injury through upregulation of NRF2 signaling. Am J Trans/ Res 2017; 9(11): 4756-4771.

24. Oleinick NL, Morris RL, Belichenko I. The role of apoptosis in response to photodynamic therapy: what, where, why, and how. Photochem Photobiol Sci 2002; 1(1): 1-21.

Trop J Pharm Res, August 2018; 17(8): 1597 
Qiao et al 